\title{
The Role of AVRDC-The World Vegetable Center in Enhancing and Promoting Vegetable Production in the Tropics
}

\author{
Manuel C. Palada, ${ }^{1}$ Thomas J. Kalb, ${ }^{2}$ and Thomas A. Lumpkin ${ }^{3}$ \\ AVRDC-The World Vegetable Center, P.O. Box 42, Shanhua, Tainan, Taiwan 74199
}

\begin{abstract}
Additional index words. Tropical horticulture, vegetable crops, developing countries, cropping systems, sustainable agriculture
\end{abstract}

\begin{abstract}
Summary. AVRDC-The World Vegetable Center was established in $\mathbf{1 9 7 1}$ as a not-for-profit international agricultural research institute whose mission is to reduce malnutrition and poverty among the poor through vegetable research and development. Over the past 30 years, AVRDC has developed a vast array of international public goods. The Center plays an essential role in bringing international and interdisciplinary teams together to develop technologies, empower farmers, and address major vegetable-related issues in the developing world. In its unique role, AVRDC functions as a catalyst to 1) build international and interdisciplinary coalitions that engage in vegetable and nutrition issues; 2) generate and disseminate improved germplasm and technologies that address economic and nutritional needs of the poor; 3) collect, characterize, and conserve vegetable germplasm resources for worldwide use; and 4) provide globally accessible, user-friendly, science-based, appropriate technology. In enhancing and promoting vegetable production and consumption in developing world, AVRDC's research programs contribute to increased productivity of the vegetable sector, equity in economic development in favor of rural and urban poor, healthy and more diversified diets for low-income families, environmentally friendly and safe production of vegetables, and improved sustainability of cropping systems. Recent achievements at AVRDC that greatly impact tropical horticulture in the developing world include virus-resistant tomatoes raising farmers income, hybrid sweet pepper breaking the yield barrier in the tropics, flood-resistant chili peppers opening new market opportunities, broccoli varieties for monsoon season, pesticide-free eggplant and leafy vegetable production systems and fertilizer systems that protect the environment. Beyond vegetable crops, AVRDC is playing an important role in expanding and promoting research and development efforts for high value horticultural crops, including fruit, ornamentals, and medicinal plants through its new Global Horticulture Initiative. AVRDC believes that horticulture crop production provides jobs and is an engine for economic growth. The important role AVRDC-The World Vegetable Center plays in developing and promoting tropical horticultural crops is discussed in this paper.
\end{abstract}

International agricultural research institutes and national agriculture ministries in developing countries are facing global challenges of rising populations, land degradation, water scarcity, pesticide abuse and widespread malnutrition. The challenges are enormous since two billion persons suffer from malnutrition due to inadequate supply and consumption of vegetables (Gardner and Halweil, 2000; UN-SCN, 2004). Furthermore, over one billion persons live on only 1 USD or less per day, and the incidence of poverty in Africa continuous to rise (Weinberger and Lumpkin, 2005). In spite of this grim condition, the opportunities for impact are greater than ever. New technologies and partnerships are creating new vistas in science that can lead to unprecedented impacts. This is an important time for vegetable research and development.

\section{THE VALUE OF VEGETABLES}

Vegetables are important and vital for healthy diets. They are absolutely essential for human health and are not a luxury (USDA, 1996). Vegetables are a rich source of many essential micronutrients, including vitamins $\mathrm{C}$ and $\mathrm{K}$, folate, thiamine, carotenes, several minerals, and dietary fiber. In fact, vegetables are the most stable and sustainable sources of micronutrients. In addition, vegetables are rich in health-related phytochemicals, such as antioxidants that play an important role in reducing the risks of many chronic diseases (AVRDC, 2002a).

\footnotetext{
${ }^{1}$ Head, Crop and Ecosystem Management Unit. ${ }^{2} \mathrm{Head}$, Communication and Training Office. ${ }^{3}$ Director General.
}

Healthy diets with vegetables improve the learning capacity and working productivity of farmers as well as all people. In contrast, poor diets lead to poor mental and physical development, poor performance in school, poor productivity in the workplace, and the likelihood of poverty in future generations (Haddad et al., 2002). Not enough vegetables are being consumed throughout the world. Two billion persons, the vast majority of whom are women and children, are not getting the micronutrients they need (Gardner and Halweil, 2000; UN-SCN, 2004). Malnutrition cannot be solved by simply producing higher quantities of food. The quality of food, and specifically, the nutrient content of the food is just as important. For example, rice, wheat and maize are among the world's most consumed staple foods, but it would require a person to eat $>5 \mathrm{~kg}$ of either of these staples each day to satisfy their requirements for vitamin $A$ and iron. Consuming a tomato and a few servings of leafy greens is a much more reasonable option for satisfying one's daily micronutrient requirements.

Vegetable production provides more jobs compared to cereal production, per hectare of production (Ali et al., 2002). It supports agribusiness and related service industries, thereby creating economic opportunities. Vegetable production diversifies and generates farm income, usually to a higher level than other agricultural products (de Bon and Tran, 2001; Ali et al., 2002). Also, vegetable production develops management and leadership skills among farmers (Weinberger, 2002). Therefore, a strong vegetable sector leads to economic growth.

\section{TRENDS IN VEGETABLE PRODUCTION}

Global production of vegetables is steadily increasing. Since 1995, worldwide production has risen at an impressive rate of $5.15 \%$ per year. However, average yields per hectare have risen only $0.79 \%$ per year, indicating the need for greater investment in research and development efforts. Production gains have been highest in developing countries, where production levels have risen $6.77 \%$ per year and yields have increased $1.08 \%$ per year over the last 10 years (FAOSTAT data, 2004). The recent growth rate for vegetable production in developing countries of Asia is quite impressive. For instance, over the past 10 years, vegetable production in developing countries of Asia has risen at the rapid pace of $7.14 \%$ per year. Since 1999 , the per capita production of vegetables in these countries has actually exceeded levels found in developed countries (Fig. 1), and can be mainly attributed to the conversion of cereal farms to vegetables (FAOSTAT data, 2004).

In contrast to the dynamic vegetable production sector in Asia, there has been slow progress in Sub-Saharan Africa, and short-term developments are very distressing. Constraints due to drought, soil degradation, underinvestment in women farmers, and the relentless HIV-AIDS and malaria epidemics have ravaged agricultural production throughout the continent (Nathan Associates, 2003). In particular, HIV-AIDS has affected vegetable cultivation, a labor-intensive enterprise. Vegetable production per capita in many countries of Africa has actually declined in recent years (FAOSTAT data, 2004). The 
Per capita vegetable production

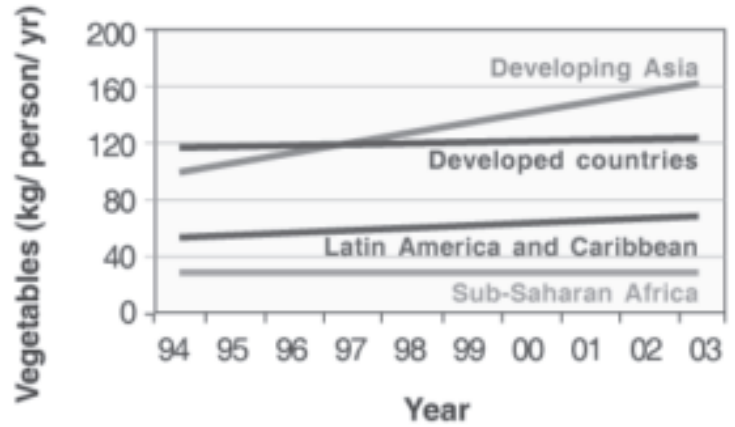

and consumption of vegetables (AVRDC, 2004a).

AVRDC serves as a catalyst to bring international and interdisciplinary teams together to develop technologies for small-scale farmers. The center is recognized as a world leader in management of diverse germplasm; innovations in crop improvement, including the use of molecular tools; sustainable production of safe and nutritious vegetables; networks of strategic alliances for generating

Fig. 1. Per capita vegetable production in Asia, developed countries, Latin America and the Caribbean and Sub-Saharan Africa. Source: FAOSTAT data, 2004.

effect of HIV-AIDS on available farm labor has been so destructive that many vegetables consumed in Africa are not cultivated, but rather gathered from uncultivated areas. These wild vegetables, including the indigenous types are essential for the food security of many families (Aphane et al., 2003)

\section{TRENDS IN VEGETABLE CONSUMPTION}

Although vegetable production is increasing at a high pace in Asia, significant postharvest losses and inadequate income contribute to widespread malnutrition. For example, in South and Southeast Asia most families do not have access to enough vegetables to live a healthy life (Fig. 2a). Malnutrition is also rampant in Latin America and the Caribbean, where per capita vegetables supplies are only $71 \%$ of what are needed for healthy diets and where obesity from imbalanced diets is rapidly increasing (Fig. 2b). The region of greatest need is in Sub-Saharan Africa, where millions of persons are threatened with severe hunger. Most Africans do not have sufficient access to food, let alone vegetables. For example, per capita vegetable supplies in the region are only $43 \%$ of what are needed (Fig. 2 c). These conditions are intolerable, and yet, they are projected to worsen (AVRDC, 2005a). The International Food Policy Research Institute predicts an 18\% rise in the number of malnourished children from 2001 to 2020 (IFPRI, 2001).

Vitamin A deficiency (VAD), which is largely due to inadequate consumption of vegetables, causes tens of thousands of children to go blind each year and raises each child's risk of death from infectious diseases, the leading causes of childhood mortality in developing countries (FAO-ILSI, 1997). In pregnant women, VAD causes night blindness and increases the risk of maternal mortality.

\section{AVRDC'S UNIQUE ROLE}

AVRDC-The World Vegetable Center is the leading international center for vegetable research and development. Its mission is to reduce poverty and malnutrition in less developed countries through improved production and sharing knowledge; and analysis of direct and indirect impacts of vegetable production and consumption. AVRDC forms alliances of partners with complementary expertise to create synergies and to increase efficiency. For example, AVRDC is a partner in the Global Horticulture Assessment and Global Horticulture Initiative, which include a vast network of international and local organizations. The center is collaborating with CGIAR centers in the areas of insect pest control (CIAT and IITA), peri-urban agriculture (CIP), cropping systems (ICRISAT, CIMMYT, IRRI and WARDA), integrated pest management (ICIPE), assisting HIV/AIDS impacted regions (ICRAF), and developing policies related to fruit and vegetables (IFPRI).

\section{MAIN OBJECTIVES OF AVRDC}

Productivity. The major focus of research and development activities at AVRDC is increasing productivity. This is the first step to improving nutrition. A study has shown that a $1.0 \%$ increase in agricultural productivity in developing countries leads to a reduction in the malnutrition of children by at least $0.4 \%$ (Thirtle et al., 2000). Increasing productivity will increase the poor's access to nutritious vegetables, which in turn will lead to healthier diets and improved worker productivity and income.

Fig. 2. (top) Per capita vegetable supplies in most populous countries of South and Southeast Asia. Source: FAOSTAT data, 2004 (middle) Per capita vegetable supplies in most populous countries of Latin America and the Caribbean. Source: FAOSTAT data, 2004. (bottom) Per capita vegetable supplies in most populous countries of Sub-Saharan Africa.
To increase yields, AVRDC is placing greater emphasis on the development of hybrid varieties. The natural boost of vigor possessed by hybrids is being used to fight the stresses of disease, heat and drought. Impressive advances at AVRDC have been made in developing hybrid tomato and pepper lines that can match the performance of many popular varieties grown in developing countries. Protocols to assist private seed companies and NARES in producing hybrid seed are being developed and disseminated though training and on-line communications.

Stability. AVRDC is focused on improving stability. Disease, heat, drought and flooding all threaten stability of vegetable supplies. In

\section{Per capita vegetable supplies}

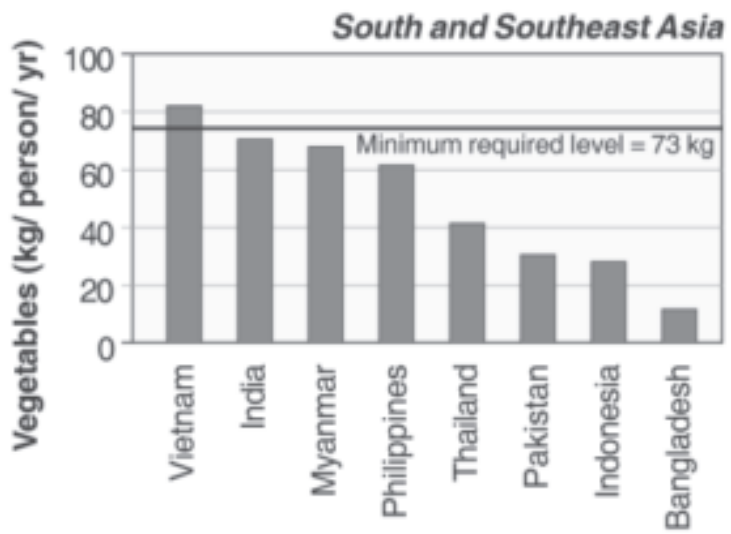

Regional average: $54.3 \mathrm{~kg} /$ person/yr
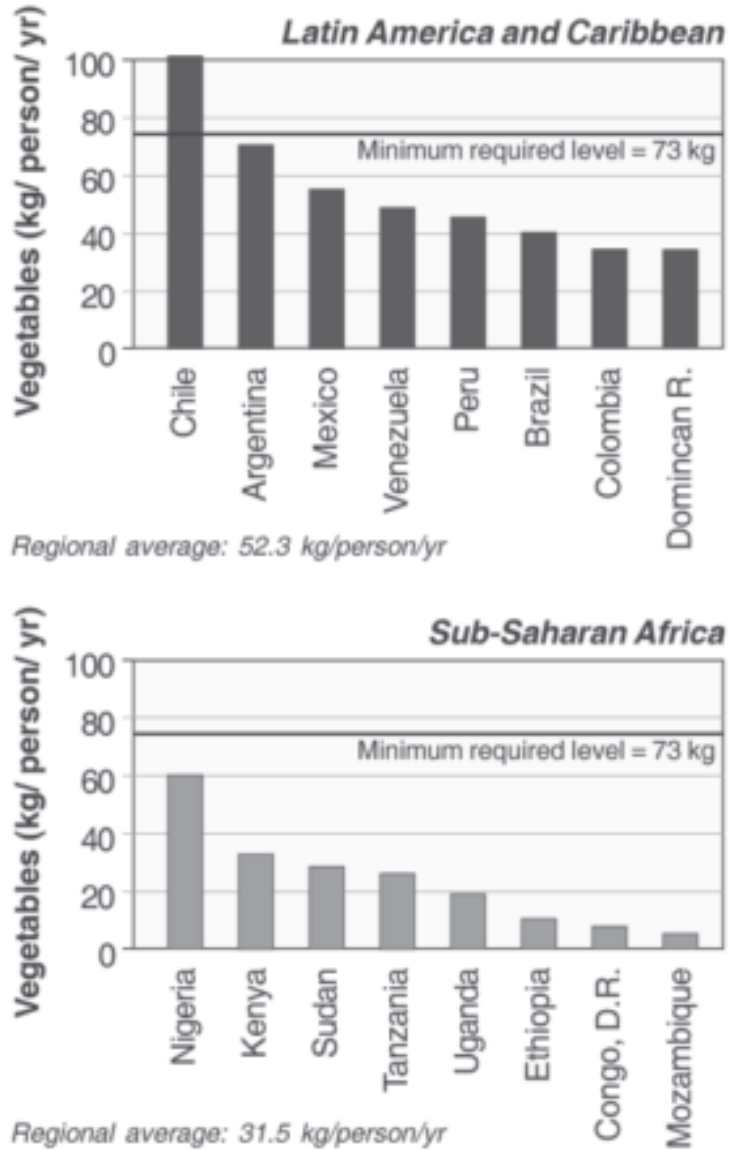
this regard, AVRDC's variety improvement programs have made remarkable impact in recent years. For example, our team of plant breeders, pathologists and biotechnologists developed high quality tomato lines that resist leaf curl geminiviruses, the major constraint of tomato production in the tropics. Another breakthrough was the discovery of the first cultivated pepper (Capsicum annuum) lines with resistance to anthracnose. This discovery makes it easier than ever for seed companies and national agricultural research and extension systems) NARES to incorporate this resistance into their varieties.

To extend and transfer this technology, AVRDC will share this germplasm with all nations and all seed companies. There is a dramatic increase in the use of AVRDC germplasm by private seed companies. A recent survey showed that free access to this germplasm especially benefits small and young companies. In fact, $50 \%$ of tomato varieties released by such seed companies in Asia contain AVRDC germplasm (AVRDC, 2003).

Sustainability. AVRDC has been focusing on increasing sustainability of vegetable production in the tropics. For example, the center has been a leader in the introduction of soybean and mungbean lines throughout the world. Soybean is the only major staple crop that sustains both human health and the environment. Among staple crops, its dietary protein is of the highest quality and quantity. Since soybean is a legume, its roots can fix nitrogen from the air and transfer it to the soil, thereby enriching the fertility of the land (AVRDC, 2004b). AVRDC's soybean lines are the principal genetic material used by NARES and seed companies in breeding varieties grown by millions of farmers in the tropics and subtropics. These lines are the only source of genetic resistance to soybean rust, one of the most severe diseases in developing countries today and a major threat to world food security.

Food safety. AVRDC is focused on ensuring food safety. Many of today's growers are inappropriately using toxic pesticides, thereby threatening the health of themselves and consumers. In peri-urban projects of AVRDC in Southeast Asia, it has been observed that growers spray their leafy vegetable crops the day of harvest, and sometimes even on the piles of harvested produce before it goes to market. A recent study in Bangladesh revealed that many eggplant growers spray their crops over 80 times per growing season using mixtures of nonregistered pesticides (Rashid et al., 2003). This practice poses a great risk to farmers, not to mention consumers and the environment. Accessibility to safe vegetables must be provided to all people. AVRDC is working with its partners to develop technologies that are safe to farmers, consumers and the environment (Palada et al., 2005). Innovative technologies, such as insect barriers and pheromone traps, are significantly reducing and sometimes eliminating the need to spray insecticides on leafy vegetables, eggplant and other vegetables. Disease-resistant varieties are another natural means that millions of farmers use to reduce the need for applying pesticides (AVRDC, 2005a; Palada et al., 2005).

Welfare of poor families. The overall goal of AVRDC research and development activities is improving the welfare of poor families. For that reason, socio-economics is an integral element of all projects. This expertise is helpful to understand the needs of clients before a project begins, the effects of a project during its implementation and finally the ultimate impacts. AVRDC is particularly sensitive to the impacts of its technologies on women, who are the principal producers and marketers of most vegetable crops. AVRDC supports the empowerment of women through its educational programs and by promoting rural economies. In the 1970s, only $27 \%$ of AVRDC trainees were women; now, $50 \%$ of the trainees are women (AVRDC, 2004a). Several AVRDC programs, including initiatives in Africa on indigenous vegetables as well as nutritional studies in South Asia, are specifically targeted toward improving the livelihoods of women (AVRDC, 2005a).

\section{IMPACT OF AVRDC TECHNOLOGIES IN TROPICAL VEGETABLE PRODUCTION}

AVRDC has significantly contributed to increased vegetable production in the tropics mainly in developing improved varieties and sustainable production practices. Some of these are highlighted under this section.

\section{Improved varieties}

Tomato. Millions of farmers currently grow tomato varieties that originated at AVRDC. In 2004, AVRDC released its finest quality, most nutritious tomato lines that are resistant to multiple diseases. These lines will assure growers of stable yields and success at the market. Among these lines are golden tomatoes which provide 3 to 6 times more beta-carotene than standard types. This trait is valuable since vitamin A deficiency is linked to the deaths of thousands of people every day. These lines are being distributed throughout Asia and SubSaharan Africa (AVRDC, 2003).

Bacterial wilt is the most severe disease affecting tomato production in the rainy season. AVRDC has developed varieties that are resistant to various strains of the disease, but complete resistance is yet to be achieved. In 2004,AVRDC developed management practices that destroy these bacteria in the soil. When these practices are combined with the use of resistant varieties, farmers have greater assurance that they can grow tomato crops in the rainy season, when profits are greatest (AVRDC, 2004b).

Through the Cambodia-Lao PDR-Vietnam Network (CLVNET), AVRDC and its national research partners are introducing AVRDC varieties to farmers. The results of on-farm testing have been very impressive. AVRDC varieties outyielded the standard varieties by $20 \%$ or higher. With support from Asian Development Bank (ADB), AVRDC research partners are now producing seed of these varieties and promoting them to farmers throughout the region (AVRDC, 2004a).

Pepper. The production of sweet pepper in the tropics is limited by excessive heat and numerous diseases. Hybrid vigor may be used to develop lines that tolerate such stresses. Using the vast collection of pepper germplasm, AVRDC has developed hybrids that either match or outperform many popular varieties in Southeast Asia for yield. Breeders from South Korea and AVRDC have released the world's first pepper lines that resist anthracnose disease. Once bred into commercial varieties, these sources of natural resistance will protect crops, reduce the need for fungicides and increase farmer profits.

Flooding during the rainy season will destroy pepper crops. AVRDC has developed chilli pepper lines which tolerate flooding. These lines can be used for production in flood-prone areas or be used as rootstocks for production during the summer when market prices are highest (AVRDC, 2004a).

Broccoli. In the rainy season, most broccoli varieties suffer from diseases and low yields. AVRDC scientists evaluated varieties from throughout the world and have identified 10 varieties that will reliably produce yields exceeding 10 tons/ha in the summer. Farmers can grow these lines during the rainy season to maximize their profits (AVRDC, 2004a).

Mungbean. The monocropping of cereal crops is reducing soil fertility and depleting water tables in South Asia. These practices are not environmentally sustainable. With support from DFID of the UK, AVRDC, and a team of scientists from Bangladesh, India, Nepal, Pakistan and Sri Lanka have developed mungbean varieties that can fit into the fallow period of this cropping system. The varieties have been enthusiastically adopted by farmers and planted on $>3$ million ha. Studies show that adding mungbeans into the rice-wheat rotation in India increases farmers'net incomes by $27 \%$ (AVRDC, 2002b). The mungbean crops enrich the farmland and provide valuable protein and iron to the diets of the people. In 2004, AVRDC led a team of seed companies, government agencies and farmers to produce seeds for planting 1.5 million ha in India, Bangladesh and Nepal (AVRDC, 2004b). The introduction of these seeds into the region has improved diets, sustained soils and increased farm incomes. Previous studies also indicated that the introduction of AVRDC mungbeans into China, Myanmar, Pakistan and Thailand led to economic gains of $\$ 98, \$ 27, \$ 20$, and $\$ 18$ million per year, respectively (AVRDC, 2002b).

Soybean. Soybean is one of the most widely grown crops in the world today. This legume is also very nutritious, containing high levels of protein, iron and numerous vitamins. In spite of its nutritional value, many people in developing countries will not eat soybean due to its objectionable flavor. Recently, AVRDC and Japanese scientists have identified a vegetable soybean, 'Dada-cha-mame', with special fragrance similar to fragrant Basmati rice(AVRDC, 2003). This flavor breakthrough is expected to have immediate impact. Fragrant soybeans can generate new sources of income for poor farmers through both marketing of harvested crops as well as home-based marketing of processed products such as soymilk and sprouts. The diets of the poor may be 
significantly improved, especially in countries where vegetarian-based, protein-deficient diets predominate (AVRDC, 2004b).

Onion. AVRDC has developed red onion lines that produce $50 \%$ higher yields and $70 \%$ larger-sized bulbs than the most widely grown variety, 'Red Creole'. In 2004, AVRDC developed lines that store better than 'Red Creole'. These new onion lines offer greater marketing opportunities for farmers (AVRDC, 2005a).

\section{Sustainable production practices}

AVRDC has been developing technologies for sustainable vegetable production systems. The objectives are to 1) identify crops and develop technologies for improved water and fertilizer use efficiencies; 2) reduce pesticide abuse and environmental degradation; and 3 ) produce pesticide-free vegetables for safe consumption.

Improved fertilizer use efficiency. High levels of fertilizer are used in the production of leafy vegetables, creating risks of harmful nitrate levels in vegetables as well as pollution caused by the leaching of nitrates into water supplies. AVRDC has developed nitrogen monitoring systems that farmers can easily use in the field. These monitoring systems can help farmers produce safe vegetables, protect the environment and maximize their profits by using fertilizers more efficiently (Ma and Palada, 2005). AVRDC has also developed a starter solution technology for vegetable production which can reduce the use of inorganic fertilizers by as much as 50\% (Ma and Kalb, 2004; Palada et al., 2005).

Improved water use efficiency. Water is increasingly becoming a scarce resource even in the humid tropics. The situation is worse during the dry season in most of the developing countries. With this scarce resource, there is a need to develop technologies that promote efficient use of water and fertilizers in vegetable production. AVRDC has initiated a project on drip irrigation to address this problem. Compared to furrow irrigation, drip irrigation uses less water, improves yield and quality of vegetables, promotes efficient use of fertilizers and reduces the risk of ground water contamination. Studies show that water use in drip irrigation was $45 \%$ to $77 \%$ less than furrow irrigation and yields of tomato, peppers and yardlong bean achieved under drip irrigation were almost similar or better than furrow irrigation. Furthermore, nutrient uptake was more efficient in drip irrigated vegetables (Palada and $\mathrm{Wu}, 2005$ ).

Pesticide-free eggplant and leafy vegetables. Eggplant fruit and shoot borer is the most serious pest of eggplant in Asia and East Africa. To combat the pest, it is common for farmers to spray their crop 80 or more times, usually using unapproved chemicals. AVRDC and counterparts in Bangladesh, India and Thailand have developed a simple strategy. This approach involves clipping damaged shoots to remove the larvae, using sex pheromones to trap moths, and allowing natural predators to attack the borers. The method is now being extended to farmers throughout the region (Alam et al., 2003; Rashid et al., 2003).
Leafy vegetables are gaining popularity, but producing them safely is getting tougher than ever. Insect pests are developing resistance to many of the most widely used pesticides. In research sponsored by the governments of France, Germany, Taiwan, and the U.K., AVRDC has developed systems that produce safe vegetables under net structures (Talekar et al., 2003). This strategy, verified in tests by farmers in Cambodia, Philippines and Vietnam, produces safe vegetables with no pesticide use.

\section{NEW INITIATIVES AT AVRDC}

AVRDC is expanding its research and development activities to new regions of the globe, and reaching out to a broader base of clientele. The following are some of the new initiatives for 2006

Affordable drip irrigation for small-scale farmers. Scarcity of water prevents many small-scale farmers from generating income and escaping poverty. Technologies are needed to help farmers make every drop of available water contribute to production. With this in mind, AVRDC has joined forces with International Development Enterprises (IDE) to refine and disseminate low-cost drip irrigation for farmers. These systems, which operate by gravity, can irrigate $1000-\mathrm{m}^{2}$ garden plots at the cost of about $\$ 10$ to $\$ 15$. Crops grown using such systems show water savings of up to $50 \%$ and reduced labor costs. IDE reports that these technologies enable smallholders to produce higheryields and earn an average of more than USD $\$ 100$ in extra net income per year (Postel et al., 2003). More than 50,000 farmers in South Asia are already using these kits and AVRDC is extending this technology through its development projects in Southeast Asia and Africa.

Organic vegetable production. Millions of subsistence farmers do not purchase chemical inputs. These farmers could increase their crop yields if they were provided with information and training in science-based organic production techniques. An international survey recently concluded there is a lack of research in organic agriculture systems especially for vegetable production in the tropics (Stoll, 2003). Nearly all of AVRDC's existing technologies are compatible with organic agriculture. With this strong foundation to build upon, AVRDC has launched a new program on organic production technologies for vegetables. The center will focus on components that solve problems specific to organic farming systems, such as sustainable soil management, disease-resistant varieties, and biological pest control methods (Palada et al., 2005).

Health-promoting properties in vegetables. Many vegetables are rich in antioxidants, which are reported to reduce risks of certain cancers and age-related diseases. AVRDC scientists are analyzing the antioxidant properties of the most diverse collection of vegetables in the world. Lycopene, beta-carotene, phenols and other functional properties are being measured. AVRDC has already identified superior species and varieties of vegetables to focus future research upon. AVRDC is also developing protocols to efficiently analyze for functional properties in the hope of developing new varieties that will prevent cancer.

Cucurbit breeding. Cucurbits include a variety of high value crops (e.g., cucumbers, melons, gourds and squashes) that play important roles both in local diets and as cash crops in developing countries. Shared interests among AVRDC and selected universities, NARES and the private seed sector have recently created new opportunities for collaborative research in cucurbit breeding. A major limitation to production of cucurbits worldwide is infection of virus diseases, many of which can reduce yields by $50 \%$ to $100 \%$. AVRDC will work with its partners to develop virus resistance in cucurbits, using a combination of molecular genetics and conventional breeding approaches. Another research thrust will be expanding the evaluation of indigenous cucurbit germplasm collection for potential use. AVRDC will also conduct expeditions in Central and Southeast Asia, where many cucurbits originate, to find new resources of desirable genes for breeding purposes.

Linking farmers to markets. Consumer demand for vegetables is rising, both in domestic and international markets. The expansion of global trade is creating a boom of new marketing opportunities for farmers, but these markets have high quality requirements, food safety standards and complex food supply chains. AVRDC believes that linking farmers to markets is vital for alleviating poverty in rural communities. The center's new postharvest initiative will assist farmers, communities and government agencies to become more market oriented. With funding from the Asian Development Bank, AVRDC will work with specialists in Cambodia, Lao PDR and Vietnam to develop postharvest technologies such as shipping and processing varieties and low-cost postharvest facilities. The aim is to generate employment opportunities and new sources of income for poor families in rural communities. Besides introducing affordable technologies, this project will assess marketing systems within the region and develop strategies to identify niche marketing opportunities for micro-enterprises.

Global horticulture. The World Vegetable Center is taking leadership in the development of global horticulture. Beyond vegetable crops, AVRDC is playing an important role in expanding and promoting research and development efforts for high value horticultural crops through its new Global Horticulture Initiative (GHI). AVRDC believes that a strong horticulture sector is an engine for economic growth because it creates jobs, supports agri-business and generates income to a greater degree than cereal crops. The mission of the GHI is to improve the health and income of the poor in developing countries through sustainable horticultural production, processing and marketing systems. Priority crops include solanaceous vegetables, legumes, crucifers, cucurbits, tropical and subtropical tree fruits, and indigenous horticultural crops. Suggested research themes include information management and dissemination; germplasm conservation and 
evaluation; genetic improvement; sustainable production technologies; postharvest storage, processing and marketing; and impact analysis and policy planning (AVRDC, 2005b).

\section{CONCLUSION}

The role of AVRDC-The World Vegetable Center in promoting and enhancing vegetable production in the tropics is very important. The center has developed improved vegetable varieties and sustainable production practices that are being adopted by small-scale farmers in Asia and Africa. These technologies have impacted vegetable production to a great extent through increased productivity and reduced negative environmental impact in selected countries. AVRDC is expanding its activities globally, reaching Latin America and the Caribbean, Central and South Asia, Central and West Africa, and the Pacific Island nations. Through the Global Horticulture Initiative (GHI) AVRDC will develop and promote technologies addressing major problems in vegetable production in these regions.

\section{Literature Cited}

Alam, S.N., M.A., F.M.A. Rashid, R.C. Rouf, J.R. Jhala, S. Patel, T.M. Satpathy, S. Shivalingaswamy, I. Rai, A. Wahundeniya, A. Cork, C. Ammaranan, and N.S. Talekar. 2003. Development of an integrated pest management strategy for eggplant fruit and shoot borer in South Asia. Shanhua, Taiwan:AVRDC-The World Vegetable Center. Tech. Bul. 28. AVRDC Publication No. 03-548.

Ali, M., U. Farooq, and Y.Y. Shih. 2002. Vegetable research and development in the ASEAN region: a guideline for setting priorities, p. 20-64. In: C.G. Kuo (ed.). Perspective of ASEAN cooperation in vegetable eresearch and development. AVRDC, Shanhua, Taiwan.

Aphane, J., M.L. Chadha, and M.O. Oluoch. 2003. Increasing the consumption of micronutrientrich foods through production and promotion of indigenous foods. FAO-AVRDC Intl. Wkshp. Proc., 5-8 Mar. 2002, Arusha, Tanzania. AVRDC-The World Vegetable Center, Shanhua, Taiwan. AVRDC Publ. 03-561.
AVRDC. 2002a. Vegetables are vital: healthy diets, productive farmers, strong economies. Asian Veg. Res. Dev. Ctr., Shanhua, Taiwan. 29 pp.

AVRDC. 2002b. AVRDC report 2001. Methodologies for impact assessment in vegetable and mungbean research, p. 59-60. AVRDC Publ. 02-542. AVRDC-The World Vegetable Center, Shanhua, Taiwan.

AVRDC. 2003.AVRDC Report 2002.AVRDC Publ. 03-563. AVRDC-The World Vegetable Center, Shanhua, Taiwan.

AVRDC. 2004a. AVRDC Medium-term plan: 2004-2006. Highlights. AVRDC-The World Vegetable Center, Shanhua, Taiwan.

AVRDC. 2004b.AVRDC report 2003.AVRDC Publ. 04-599. AVRDC-The World Vegetable Center, Shanhua, Taiwan.

AVRDC. 2005a. AVRDC medium-term plan 2005-2007. AVRDC-The World Vegetable Center, Shanhua, Taiwan.

AVRDC. 2005b. The Global Horticulture Initiative: A project proposal.AVRDC-The World Vegetable Center, Shanhua, Taiwan.

de Bon, H. and K.T. Tran. 2001. The response of peril-urban agriculture to urbanization in Vietnam. FAO Paper EC600E.

FAO-ILSI (Food and Agriculture Organization of the United Nations-International Life Sciences Institute). 1997. Preventing micronutrient malnutrition: a guide to food-based approaches. Why policy makers should give priority to food-based strategies. ILSI Press, Wash., D.C.

FAOSTAT data. 2004. Accessed June 2005.

Gardner, G. and B. Halweil. 2000. Underfed and overfed: the global epidemic of malnutrition. Worldwatch paper 150. Worldwatch Inst. Wash., D.C.

Haddad, L., H. Alderman, S. Appleton, L. Song, and Y. Yohannes. 2002. Reducing child undernutrition. How far does income growth takes us? Intl. Food Policy Res. Inst. (IFPRI), Food Consumption Nutr. Div., Wash., D.C.

IFPRI (International Food Policy Research Institute). 2001. Empowering women to achieve food security: vision 2020. Focus 6. IFPRI. Wash., D.C.

Ma, C.H. and T. Kalb. 2004. Development of starter solution technology as a balanced fertilization practice in vegetable production. Acta Hort. (in press).

Ma, C.H. and M.C. Palada. 2005. In-situ N monitoring for safe leafy vegetables using quick and advanced tools. HortScience 40:1074.

Nathan Associates. 2003. RCSA food security strategic option: Synthesis and analysis of selected readings. U.S. Agency Intl. Dev. (in press).

Palada, M.C., J.W. Wang, R. Srinivasan, and C.H.Ma. 2005. AVRDC-The World Vegetable Center's present and future approaches to good agricultural practices. Proc. Intl. Sem. Technologies for Good Agriculture Practice in Asia and Oceania. Tsukuba, Japan. 25-26 Oct. 2005 (in press).

Palada, M.C. and D.L. Wu. 2005. Influence of rain shelter and irrigation method on yield, water and fertilizer use efficiency of chili pepper. HortScience 40:1143.

Postel, S., P. Polak, F. Gonzales, and J. Keller. 2003. Drip irrigation for small farmers: A new initiative to alleviate hunger and poverty. Intl. Dev. Enterprises (India) Rpt. 014.

Rashid, M.A., S.N. Alam, F.M.A. Rouf, and N.S Talekar. 2003. Socio-economic parameters of eggplant pest control in Jessore District of Bangladesh. AVRDC-The World Vegetable Center, Shanhua, Taiwan. AVRDC Publ. 03-556.

Stoll, G. 2003. Background study on the current state of organic agriculture research in horticulture and its perspective in Asia. Rpt. BMZ-GTZ, AVRDC, and IFOAM.

Talekar, N.S., F.C. Su, and M.Y. Lin. 2003. How to produce safer leafy vegetables in nethouses and net tunnels. Asian Vegetable Research and Development Center, Shanhua, Tainan, Taiwan.

Thirtle, C., X. Irz, L. Lin, V. McKenzie-Hill, and S. Wiggins. 2000. Relationship between changes in agricultural productivity and the incidence of poverty in developing countries. DFID Rpt. 7946.

United Nations System Standing Committee on Nutrition (UN-SCN). 2004. 5th Rpt. on the world nutrition situation. Nutrition for improved development outcomes. World Health Organization, UN-SCN, Geneva.

U.S. Department of Agriculture. 1996. The food guide pyramid. Ctr. Nutr. Policy Promotion, Wash., D.C. Home and Garden Bul. 252.

Weinberger, K. 2002. Survey of vegetable and non-vegetable farmers. AVRDC unpublished report.

Weinberger, K. and T.A. Lumpkin. 2005. Horticulture for poverty alleviation - the unfunded revolution. Shanhua, Taiwan:AVRDC-The World Vegetable Center, Shanhua, Taiwan. AVRDC Publ. 05-613 Working Paper 15. 